\title{
Kurumsal Yönetim Derecelendirme Notu İle İşletmelerin Finansal Başarıları Arasındaki İlişskinin İncelenmesi
}

\author{
Nilgün KAYALI* \\ İrem DOĞAN ${ }^{* *}$
}

\begin{abstract}
ÖZET
Kurumsal yönetim derecelendirme notu işletmelerin kurumsal yönetim ilkelerine uyumu doğrultusunda değerlendirilerek, derecelendirme notu vermeye yetkili bir kuruluş tarafindan verilen notu ifade etmektedir. Bu kapsamda; işletmelerin paydaş haklarına verdikleri önem düzeyinin artması, kamuyu aydınlatma kapsamında gerçekleştirilen faaliyetlerin istenilen düzeyde olmasl, işletmelerin kredibilitesini arttırarak, kurumsal yönetim derecelendirme notunu da olumlu yönde etkilemektedir. Diğer açıdan, yaşanan global krizler ve işletme iflasları paydaşların işletmelere duydukları güven düzeyinin azalmasına sebep olmakla birlikte, hem kurumsal yönetimin önemini hem de yatırım açısından işletmelerin finansal başarılarının iyi bir düzeyde olması gerekliliğinin önemini arttırmıştır.

Çalışmamızın amacı, Borsa İstanbul (BİST) Kurumsal Yönetim Endeksinde yer alan imalat sektöründeki işletmelerin 2012-2016 yılları arasinda aldıkları kurumsal yönetim derecelendirme notu ile finansal başarıları arasındaki ilişkinin incelenmesidir. Işsletmelerin finansal başarılarının veya yatırım açısından risk taşıyıp, taşımadı̆̆ının incelenmesi için literatürde sıkça kullanılan Altman (1968), Springate (1978), Fulmer vd. (1984) ve Zmijewski (1984) modellerinden yararlanılmıştır. Çalışma sonuçlarımız doğrultusunda, işletmelerin kurumsal yönetim derecelendirme notu arttıkça iflas olasılıklarının azaldı̆̆ ve dolayısı ile finansal başarılarının arttı̆̆ tespit edilmişstir.
\end{abstract}

Anahtar Kelimeler: Kurumsal Yönetim, Kurumsal Yönetim Derecelendirme Notu, Finansal Başarı

JEL Sinıflandırması: M40, M42, M49.

\section{Examination Of The Correlation Between Corporate Governance Rating Score And Financial Success of Enterprises}

\section{ABSTRACT}

Corporate governance rating score expresses the score given by an institution authorized to give a rating score by as-sessing the managements in accordance with the principles of corporate governance. In this context, the fact that the importance level given by the managements to shareholders' rights increases and that the activities conducted within the context of enlightening the public are at the desired level affect positively corporate governance rating score by increasing the credibility of managements. On the other hand, the experienced global crises and managements' going bankrupt causes the confidence levels of shareholders to managements to get decreased, while they have increased both the importance of corporate governance and the importance of the necessity that the financial success of managements should be at a good level in terms of investment.

This study aims to examine the correlation between the 2012-2016 corporate governance rating scores and financial success of the manufacturing enterprises in the BIST Corporate Governance Index. For investigating the financial success of the enterprises or whether the enterprises pose risk in terms of financial success, the models introduced by Altman (1968), Springate (1978), Fulmer vd.. (1984) and Zmijewski (1984) which are frequently used in the literature were utilized. In accordance with the results of the study, it was found that en-terprises' possibility of bankruptcy decreases, therefore increasing their financial success as their corporate governance ra-ting score increases.

Keywords: Corporate Governance, Corporate Governance Rating Score, Financial Success.

Jel Classification: M40, M42, M49.

\footnotetext{
* Doç. Dr. Nilgün Kayalı, Manisa Celal Bayar Üniversitesi, İktisadi ve İdari Bilimler Fakültesi, nilgunkayali2002@yahoo.com.

** İrem Doğan, Manisa Celal Bayar Üniversitesi, Sosyal Bilimler Enstitüsü, , İrmdgn_89@hotmail.com.
} 


\section{GíRiş}

Kurumsal yönetim; işletmeler ve muhasebe bilgi kullanıcıları açısından oldukça büyük önem arz etmektedir. İşletmeler çeşitli kriterleri sağladıkları durumda BİST Kurumsal Yönetim Endeksine dahil olmaktadır. Aynı zamanda, kurumsal yönetim çabaları doğrultusunda gerçekleştirilen faaliyetlerin istenilen düzeyde olması veya artması işletmelerin kurumsal yönetim derecelendirme notuna yansıtmaktadır. Bununla birlikte, muhasebe bilgi kullanıcıları yatırım yapacakları işletmelerin kurumsal yönetim ilkelerine üst düzeyde uyum sağlamasını ve finansal performanslarının (başarılarının) da üst düzey'de olmasını talep etmektedirler.

$\mathrm{Bu}$ doğrultuda çalışmamızın amacı; BİST Kurumsal Yönetim Endeksinde yer alan İmalat Sektöründeki işletmelerin 2012-2016 yıllarında aldıkları kurumsal yönetim derecelendirme notu ile finansal başarıları arasındaki ilişkinin incelenmesidir.

\section{LITERATÜR ÖZETI}

Literatür incelendiğinde, BİST'te çeşitli sektörlerde yer alan işletmelerin finansal başarılarının incelenmesi amacı ile iflas tahmin yöntemi olarak geliştirilen modellerin sıkça kullanıldığı görülmektedir. Söz konusu çalışmalardan bazıları aşağıda yer aldığı gibidir.

Bozkurt (2014), sistematik risklerde meydana gelen artışın en iyi açıklayan modeli tespit etmeyi amaçlamıştır. Bu amaçla çalışmasında; Altman Z Skoru Modeli’ nin yer aldığ1 sekiz farklı modeli kullanarak BİST' te işlem gören 168 işletmenin iflas olasıllklarını incelemiştir. Çalışma sonuçları doğrultusunda; Altman-Z”, Ohlson-O ve Springate-S iflas modellerinin BIST Endeksinde sistematik risklerde meydana gelen değişimi daha iyi açıkladığını ifade etmiştir.

İskenderoğlu ve Karakozak (2013) çalışmalarında, BİST imalat sektöründe yer alan işletmelerin 2007-2011 yılları arasında ara dönem finansal raporlarında yer alan bilgileri kullanarak ve Altman Z Skoru Modeli aracılığı ile iflas risklerini incelemişlerdir. Bu çalışma sonuçları göre, söz konusu işletmelerin 2008 yılının ilk çeyrek döneminden, 2009 yılının son çeyrek dönemine kadar iflas risklerinde artış olduğunu tespit etmişlerdir.

Kulalı (2016) çalışmasında, Altman Z Skoru Modeli aracılığı ile 2000-2013 yılları arasında BIST Endeksinde işlem gören ve iflas yaşayan işletmelerin finansal performanslarını değerlendirmiştir. Çalışma sonuçları doğrultusunda, Altman Z Skoru Modeli'nin işletme iflaslarının tahmin edilmesinde oldukça etkili olduğunu ifade etmiştir.

Muigai (2016) çalışmasında, 2004-2013 yıllarında Altman Z Skor Modeli’ni kullanarak Kenya'da bulunan işletmelerin finansal başarısı ile sermaye yapısı kararları arasındaki ilişkiyi incelemiştir. Çalışma sonuçları doğrultusunda; Altman Z Skoru arttıkça uzun vadeli borç oranının da arttığını ifade etmiştir. Aynı zamanda, Altman Z Skorunun artması ile finansal kaldıraç oranın'da azaldığını belirtmiştir.

Yıldız (2014) çalışmasında, ikili lojistik regresyon yöntemini kullanarak, BİST 100 Endeksinde yer alan işletmeleri çalışma kapsamına dahil etmiştir. Çalışma sonuçları doğrultusunda, işletmelerin yatırım yapılabilecek düzeyde olmaları ile Altman Z skoru 
arasında anlamlı bir ilişki tespit edilirken, kurumsal yönetim endeksi ile işletmelerin yatırım yapılabilecek düzeyde olmaları arasında istatistiksel açıdan anlamlı bir ilişki olmadığını ifade etmiştir.

\section{KURUMSAL YÖNETIM DERECELENDİRME NOTU}

Dünya genelinde yaşanan hızlı değişim ve gelişim, sermaye piyasalarına da uluslararası fonlara kolayca ulaşılabilmesi şeklinde yansımıştır. Ancak bu firsat, mevcut veya potansiyel yatırımcıların iletişim konusunda yöneticilerle yaşayabileceği sorunları da beraberinde getirmiştir. Bu sebeple, oluşabilecek sorunların azaltılması veya önlenmesi için uluslararası uyumluluğu kapsayan bir sisteme ihtiyaç duyulmuştur. $\mathrm{Bu}$ ihtiyaç da kurumsal yönetim anlayışının oluşmasını sağlamıştır. (SPK, 2005: 1-2) Bununla birlikte, yaşanan işletme başarısızlıkları ve uluslararası boyuttaki finansal krizlerin temelinde; kurumsal yönetim anlayışının eksikliğinin anlaşılması ile de kurumsal yönetim, hem muhasebe bilgi kullanıcıları hem de araştırmacılar tarafından önem kazanarak, incelenmiş ve tartışılmıştır (Akdoğan vd., 2016:4).

Kurumsal yönetim ile ilgili farklı kuruluşlar tarafından yapılan çalışmaların varlığı söz konusu olsa da, Ekonomik İşbirliği ve Kalkınma Örgütü (OECD) tarafından 1999 yılında yayımlanan OECD Kurumsal Yönetim İlkeleri hem OECD' ye üye olan ülkeler için hem de üye olmayan ülkeler için yol gösterici kılavuz niteliğini almıştır (KYD ve OECD, 2005:4). Bu kapsamda OECD tarafından kurumsal yönetim; "bir firmanın yönetimi, yönetim kurulu, hissedarları ve diğer menfaat sahipleri arasındaki karşılıklı ilişkilerini içermektedir. Kurumsal yönetim bu guruplar arasındaki sorumluluk ve hak dağıtımını belirlemekte ve firmanın ileriye yönelik belirlemiş olduğu amaçları için karar alıcılar ile ilgili kuralları belirlemektedir." şeklinde tanımlanmıştır. Aynı zamanda söz konusu sistemin mevcut veya potansiyel yatırımcıların da getiri elde etme konusunda kendilerini güvende hissettikleri bir sistem olduğunu ifade etmek mümkündür (Shleifer ve Vishny, 1996: 2).

Ülkemizde pay senetleri, borsada işlem gören işletmeler belirlenen çeşitli kriterleri sağlamaları durumunda BİST Kurumsal Yönetim Endeksi (XKURY)'ne dahil olmaktadır. Söz konusu endeks; BİST pay senedi endekslerinden biri olup, kurumsal yönetim anlayışını benimseyen ve kurumsal yönetim ilkelerine üst düzeyde uyum sağlayan işletmelerin var olduğu bir endeksi ifade etmektedir. Kurumsal yönetim sisteminin derecelendirilmesi ise; derecelendirmeye yetkili bir kuruluş tarafından bağımsız, tarafsız ve adil olarak değerlendirilerek, sınıflandırıldığı bir faaliyettir (SPK No: 40, Madde 6). OECD ile paralel olarak ülkemizde de 2013 tarihinde Pay Sahipleri: \%25, Kamuyu Aydınlatma ve Şeffaflık: \%25, Menfaat Sahipleri: \%15 ve Yönetim Kurulu: \%35 şeklinde olmak üzere ağırlıklandırılmıştır. Söz konusu değerlendirme sonucunda işletmeler 1 ila 10 arasında bir puan almaktadır. Bu kapsamda, her bir ana başlık üzerinden en az 6,5 puana sahip olan ve toplamda en az 7 puana sahip olarak derecelendirilmiş işletmeler BİST kurumsal yönetim endeksinde yer almaktadır (Akdoğan, vd., 2016: 5). Ülkemizde 2017 yılı Mayıs ayı itibari ile 49 işletme BİST kurumsal yönetim endeksine dahil olmaktadır.

\section{FINANSAL BAŞARI}

Bir işletmenin finansal başarısı en genel anlatımla, finansal başarısızlığa veya iflasa yakın olmamaları ile değerlendirilmektedir. Başka bir açıdan ise; finansal başarısızlıktan, 
iflastan uzak olan ve muhasebe bilgi kullanıcıları açısından yatırım yapılabilecek düzeyde olan işletmelerin finansal açıdan başarılı olduğunu söylemek mümkündür. $\mathrm{Bu}$ noktada finansal başarısızlık; işletme faaliyetlerinden elde edilen nakit akışları ile işletmenin kısa vadeli yükümlülüklerini yerine getirememesi, k1sa vadeli taahhütlerin yerine getirilememesi ve söz konusu sıkıntılar nedeniyle işletmeleri önlem almaya zorlaması ile ifade edilebilmektedir (Ross vd., 2005: 832). İşletmeler tarafindan yaşanan finansal başarısızlığın her zaman iflasla sonuçlanmamakla birlikte, süreklilik arz etmesi durumunda ise son nokta iflaslar olmaktadır. Ancak yaşanan iflaslar da, sadece işletmeler boyutunda etkili olmayıp, makro düzeyde ülke ekonomisini de etkilemektedir. Bu sebeple işletmeler tarafından yaşanan finansal başarısızlık; muhasebe bilgi kullanıcıları ve araştırmacılar tarafından incelenmesi gereken bir konu olmakla birlikte, öngörmeyi ve önlem almayı gerektirmektedir.

Literatürde işletmelerin finansal başarılarını ölçmek veya değerlendirmek için çeşitli yöntemler ve modeller geliştirilmiştir. Bu yöntemlerden en sık kullanılanları iflas tahmin yöntemleri olarak da nitelendirilen modellerdir. Söz konusu modeller işletmelerin iflas risklerini öngörerek, iflasa yakınlıklarını tespit etmeyi amaçlamışlardır. Dolayısı ile iflastan uzak olan işletmelerin finansal başarılarının yüksek olduğu ifade edilmiştir.

Finansal başarısızlık veya iflası öngörebilmek için, atmış yıldan daha uzun bir süredir geliştirilen tahmin yöntemleri genel olarak; sadece iflas riskini gösteren rasyoların neler olduğunu ortaya koyan çalışmalar ve rasyoları farklı ağırlıklarla birleştirerek bir skor elde eden çalışmalar olmak üzere ikiye ayırmak mümkündür. (Bozkurt: 2014: 128). Söz konusu çalışmalar gruplandırılarak aşağıda yer alan tabloda gösterilmiştir.

Tablo 1. İflasın Öngörülebilirliğini Ortaya Koyan Çalışmalar

\begin{tabular}{|l|l|}
\hline Sadece Rasyolara Yer Veren Çalışmalar & Rasyoları Ă̆ırlıklarla Birleştiren Çalışmalar \\
\hline Beaver (1966) & Altman (1968) \\
\hline Dambolena ve Khoury (1980) & Springate (1978) \\
\hline Shumway (2001) & Ohlson (1980) \\
\hline Chava ve Jarrow (2004) & Altman (1983) \\
\hline Hillegeist vd. (2004) & Fulmer vd. (1984) \\
\hline Beaver vd. (2005) & Zmijewski (1984) \\
\hline Bharath ve Shumway (2008) & Altman (1993) \\
\hline Campbell vd. (2008) & Piotroski (2000) \\
\hline
\end{tabular}

Kaynak: Bozkurt, 2014: 128’ den özetlenerek tablo haline dönüştürülmüştür.

Tablo 1' de görüldüğü üzere; işletmelerin finansal başarısını dolayısı ile iflasa olan yakınlığını ölçen çalışmalar 1960'lı yıllarda ortaya atılmıştır. Söz konusu modeller; işletmelerin iflas olasılıklarını tahmin etmekle birlikte, finansal başarılarını ortaya koymaktadır. Bu çalışmada işletmelerin finansal başarısını ölçmek amacıyla literatürde yer alan çalışmalardan, rasyoları ağırlıklarla birleştiren modeller olan ve finansal verileri içeren Altman (1968), Springate (1978), Fulmer vd. (1984) ve Zmijewski (1984) kullanılmıştır.

\section{VERİ SETİ VE YÖNTEM}

$\mathrm{Bu}$ çalışmada; BİST Kurumsal Yönetim Endeksinde yer alan, imalat sektörü işletmelerinin öncelikle 2012-2016 yılları arasında finansal olmayan bilgilerini içeren kurumsal yönetim derecelendirme notları yıllar itibari ile incelenerek, meydana gelen 
değişiklikler ortaya konmuştur. Sonrasında finansal bilgileri içeren ve işletmelerin finansal başarılarını değerlendirmek amacı ile literatürde sıkça kullanılan ve yukarıda söz edilen Altman (1968), Springate (1978), Fulmer vd. (1984) ve Zmijewski (1984) modelleri sirasi ile kullanılarak, 2012-2016 yılları itibari ile işletmelerin finansal başarılarında yaşanan değişiklikler ortaya konmuştur. Son olarak ise, kurumsal yönetim derecelendirme notu ile finansal başarı arasındaki ilişkinin incelenmesi amacı ile korelasyon analizi kullanılmıştır. $\mathrm{Bu}$ amaçla araştırma sorusu aşağıda yer aldığı gibidir.

İşletmelerin kurumsal yönetim derecelendirme notu ile finansal başarıları arasında bir ilişki var mıdır?

Araştırma sorusu çerçevesinde araştırma hipotezleri ise aşağıda yer aldığı gibidir.

H1: Kurumsal yönetim endeksinde yer alan, imalat işletmelerinin kurumsal yönetim derecelendirme notu ile finansal başarıları arasında negatif yönlü bir ilişki vardır.

H2: Kurumsal yönetim endeksinde yer alan, imalat işletmelerinin kurumsal yönetim derecelendirme notu ile finansal başarıları arasında pozitif yönlü bir ilişki vardır.

Aynı zamanda çalışma anakütlesini BİST Kurumsal Yönetim Endeksi (XKURY)' nde yer alan 49 işletme oluşturmaktadır. Çalışma kapsamına söz konusu 49 işletmeden sadece imalat sektöründe yer alan 19 işletme dahil edilmiştir. Bunun sebebi ise, işletmelerin finansal başarılarını ölçmek için, kullanılan modellerden Altman (1968) Modeli’nin imalat sektöründe yer alan işletmeler için geliştirilmiş olmasıdır. Bununla birlikte, çalışma verilerinin toplandığ 1 dönem itibari ile çalışmanın tamamlanabilmesi için ihtiyaç duyulan verilere ulaşılamayan işletme sayısı ise, 3'tür. Tüm bu kısıtlamalardan sonra çalışma örneklemine dahil olan işletme sayısı 16'dır. Çalışmadan elde edilen veri sayısı ise her bir model için 80 (16X5)'dir. Ayrıca çalışmanın tamamlanabilmesi için, gerekli olan verilere işletmelerin kendi web sayfaları, faaliyet raporları ve kamuyu aydınlatma platformu (KAP)'nda yer alan finansal tablolarından ulaşılmıştır. Çalışma örnekleminde yer alan işletmeler Tablo 2' de yer aldığ 1 gibidir.

Tablo 2. Çalışma Örneklemi

\begin{tabular}{|c|c|c|}
\hline & Kod & İşletme Ad1 \\
\hline 1 & AEFES & ANADOLU EFES BİRACILIK VE MALT SANAYIII A.Ş. \\
\hline 2 & ARCLK & ARÇELİK A.Ș. \\
\hline 3 & AYGAZ & AYGAZ A.Ş. \\
\hline 4 & CCOLA & COCA-COLA İÇECEK A.Ş. \\
\hline 5 & HURGZ & HÜRRIYYET GAZETECILIIK VE MATBAACILIK A.Ş. \\
\hline 6 & IHEVA & İHLAS EV ALETLERİ İMALAT SANAYİ VE TİCARET A.Ş. \\
\hline 7 & OTKAR & OTOKAR OTOMOTIV VE SAVUNMA SANAYİ A.Ș. \\
\hline 8 & PETUN & PINAR ENTEGRE ET VE UN SANAYİI A.Ș. \\
\hline 9 & PINSU & PINAR SU SANAYİ VE TİCARET A.Ş. \\
\hline 10 & PNSUT & PINAR SÜT MAMULLERİ SANAYIII A.Ş. \\
\hline 11 & TOASO & TOFAŞ TÜRK OTOMOBİL FABRİKASI A.Ș. \\
\hline 12 & TRCAS & TURCAS PETROL A.Ş. \\
\hline 13 & TUPRS & TÜPRAŞ-TÜRKIYYE PETROL RAFINELERİ A.Ş. \\
\hline 14 & PRKAB & TÜRK PRYMİAN KABLO VE SISTTEMLERİ A.Ş. \\
\hline 15 & TTRAK & TÜRK TRAKTÖR VE ZİRAAT MAKİNELERİ A.Ş. \\
\hline 16 & VESTL & VESTEL ELEKTRONIK SANAYİ VE TİCARET A.Ş. \\
\hline
\end{tabular}




\subsection{Kurumsal Yönetim Derecelendirme Notu}

Finansal olmayan verileri içeren ve BİST Kurumsal Yönetim Endeksi (XKURY)'nde yer alan imalat sektörü işletmelerinin 2012-2016 yılları arasında kurumsal yönetim derecelendirme notu vermeye yetkili bir kuruluş tarafından verilen kurumsal yönetim derecelendirme notları Tablo 3' de yer aldığı gibidir.

Tablo 3. Kurumsal Yönetim Derecelendirme Notları

\begin{tabular}{|l|l|l|l|l|l|l|}
\hline & İŞLETME & $\mathbf{2 0 1 2}$ & $\mathbf{2 0 1 3}$ & $\mathbf{2 0 1 4}$ & $\mathbf{2 0 1 5}$ & $\mathbf{2 0 1 6}$ \\
\hline 1 & AEFES & 8,94 & 9,33 & 9,42 & 9,55 & 9,58 \\
\hline 2 & ARCLK & 9,11 & 9,28 & 9,41 & 9,48 & 9,52 \\
\hline 3 & AYGAZ & 8,96 & 9,27 & 9,29 & 9,36 & 9,36 \\
\hline 4 & CCOLA & 8,88 & 9,20 & 9,25 & 9,40 & 9,45 \\
\hline 5 & HURGZ & 9,09 & 9,09 & 9,30 & 9,36 & 9,28 \\
\hline 6 & IHEVA & 7,68 & 8,00 & 8,02 & 8,06 & 8,08 \\
\hline 7 & OTKAR & 8,68 & 9,10 & 9,28 & 9,32 & 9,32 \\
\hline 8 & PETUN & 8,77 & 9,16 & 9,11 & 9,20 & 9,26 \\
\hline 9 & PINSU & 9,31 & 9,34 & 9,28 & 9,37 & 9,38 \\
\hline 10 & PNSUT & 8,87 & 9,15 & 9,09 & 9,18 & 9,24 \\
\hline 11 & TOASO & 9,03 & 9,14 & 9,01 & 9,06 & 9,14 \\
\hline 12 & TRCAS & 9,40 & 8,75 & 9,09 & 9,27 & 9,35 \\
\hline 13 & TUPRS & 9,10 & 9,34 & 9,31 & 9,44 & 9,42 \\
\hline 14 & PRKAB & 8,44 & 8,65 & 9,06 & 9,09 & 9,09 \\
\hline 15 & TTRAK & 8,90 & 9,10 & 9,05 & 9,09 & 9,15 \\
\hline 16 & VESTL & 9,32 & 9,09 & 9,03 & 9,12 & 9,36 \\
\hline
\end{tabular}

\subsection{Altman (1968) Z Skor Modeli ile Finansal Başarının İncelenmesi}

1968 yılında Edward Altman tarafından geliştirilen Z Skor Modeli; literatürde iflas tahmin yöntemi olarak yer almakla birlikte işletmelerin finansal başarılarının değerlendirilmesi için sıç̧a kullanılmaktadır. Altman Z Skoru Modeli; oran analizi yönetiminde kullanılan finansal oranların ayrı ayrı değerlendirilmesinden dolayı çelişkili sonuçlara ulaştırdığı yönündeki eleştirileri elimine etmektedir. Finansal oranların aksine Altman Z Skoru Modelinde, finansal oranlar birbirleriyle etkileşim halinde ve birleştirilerek kullanılmaktadır (Altman, 1968: 589). Altman çalışmasında çok değişkenli diskriminant analizini kullanmıştır. Bu kapsamda; iflas eden 33 işletme ile finansal başarı gösteren 33 işletme olmak üzere toplam 66 işletme ile çalışmasını gerçekleştirmiştir. Altman, öncelikle; 22 tane finansal oran belirlemiş, daha sonra istatiksel analizler sonucunda ve bilgisayar programı aracılığı ile atadığı ağırlıklarla söz konusu modeli 5 grupta toplayarak geliştirmiştir (Miller, 2009: 1). Model; halka açık olan imalat sektörü işletmeleri için geliştirilmiş olup, aşağıda yer aldığı gibidir (Altman, 1968: 594).

$$
\text { Z-Skor= 1,2 X1 + 1,4 X2 + 3,3 X3 + 0,6 X4 + 1,0 X5 }
$$

Kullanılan değişkenlerin açıklamaları Tablo 4' de yer aldığı gibidir. 
Tablo 4. Kullanılan Değişkenler

\begin{tabular}{|l|l|}
\hline DEĞİŞKEN & AÇIKLAMA \\
\hline X1 & Net İşletme Sermayesi /Toplam Aktifler \\
\hline X2 & Dağıtılmamış Kâr/Toplam Aktifler \\
\hline X3 & Faiz ve Vergi Öncesi Kar/ Toplam Aktifler \\
\hline X4 & $\begin{array}{l}\text { Öz Sermayenin Cari Değeri/Borçların Defter } \\
\text { Değeri }\end{array}$ \\
\hline X5 & Net Satışlar/Toplam Aktifler \\
\hline
\end{tabular}

Kaynak: Altman, 1968: 594.

Altman Tablo 4'de yer alan oranlar ile formül (1)'de yer alan katsayıların çarpılması ile elde edilen $Z$ Skor sonucunu üç farklı bölgeye ayırmıştır. Bu bölgelerin aralıkları ve ifade ettikleri anlamları Tablo 5'de yer aldığ 1 gibidir.

Tablo 5. Altman (1968) Z Skor Açıklaması

\begin{tabular}{|l|l|}
\hline ARALIK & AÇIKLAMA \\
\hline $\begin{array}{l}Z<1.80 \text { İflas Riskli } \\
\text { (kırmızı) Bölge }\end{array}$ & $\begin{array}{l}\text { Z değerinin 1,80'in altında olması, işletmenin finansal durumunun çok büyük bir risk } \\
\text { altında olduğunu ve finansal başarısılık yaşadığını dolayısı ile kırmızı bölgede yer } \\
\text { aldığını göstermektedir. İşletmeyi finansal açıdan başarılı konuma getirmek için başka } \\
\text { bir ifade ile iflas olasılığını minumum düzeye çekmek veya yok etmek için ciddi } \\
\text { çalışmalar yapılmalıdır. }\end{array}$ \\
\hline $\begin{array}{l}\text { 1.80<Z<2.99 İflas } \\
\text { Açısından Belirsiz } \\
\text { (Gri) Bölge }\end{array}$ & $\begin{array}{l}\text { Z değerinin 1,80 ila 2,99 arasında olması, işletmenin iflas durumu açısından belirsiz bir } \\
\text { bölgede yer aldığını ve iki yıl içerisinde iflas etme olasılığının olduğunu göstermektedir. } \\
\text { Bu durum işletmeler için uyarıcı niteliğinde olup, işletmeler tarafından gerekli } \\
\text { önlemlerin alınması gerektiğine işaret etmektedir. }\end{array}$ \\
\hline $\begin{array}{l}Z>2.99 \text { Güvenli } \\
\text { (Yeşil) Bölge }\end{array}$ & $\begin{array}{l}\text { Z değerinin 2,99'un üzerinde olması, işletmenin finansal olarak başarılı olduğunu ve iflas } \\
\text { açısından risk taşımadığını göstermektedir. Ancak işletmeler sistematik risklere ve } \\
\text { beklenmedik durumlara karşı tedbirli olmalıdırlar. }\end{array}$ \\
\hline
\end{tabular}

Kaynak: Altman, 1968: 597.

Çalışma örneklemimize dahil olan işletmelerin ve 2012 ila 2016 yılları arasında Z Skor değerleri hesaplanmış ve sonuçları Tablo 6'da gösterilmiştir.

Tablo 6. Altman Z Skor Sonuçları

\begin{tabular}{|l|l|l|l|l|l|l|}
\hline \multicolumn{2}{|l|}{ IŞLETME } & \multicolumn{2}{l}{ ALTMAN Z SKOR SONUCU } \\
\hline & & $\mathbf{2 0 1 2}$ & $\mathbf{2 0 1 3}$ & $\mathbf{2 0 1 4}$ & $\mathbf{2 0 1 5}$ & $\mathbf{2 0 1 6}$ \\
\hline 1. & AEFES & 2,020 & 2,080 & 1,869 & 1,626 & 1,591 \\
\hline 2. & ARCLK & 2,126 & 2,091 & 2,129 & 2,082 & 2,037 \\
\hline 3. & AYGAZ & 3,580 & 4,167 & 4,146 & 3,777 & 3,624 \\
\hline 4. & CCOLA & 2,320 & 1,803 & 1,969 & 1,751 & 1,652 \\
\hline 5. & HURGZ & 1,483 & 1,129 & 0,547 & 0,821 & 0,762 \\
\hline 6. & IHEVA & 2,611 & 1,868 & 1,581 & 3,261 & 2,677 \\
\hline 7. & OTKAR & 1,668 & 1,602 & 1,468 & 1,399 & 1,430 \\
\hline 8. & PETUN & 2,681 & 3,700 & 4,046 & 4,155 & 4,024 \\
\hline 9. & PINSU & 2,414 & 1,387 & 1,794 & 1,000 & 0,549 \\
\hline 10. & PNSUT & 2,238 & 3,334 & 3,272 & 3,398 & 2,794 \\
\hline
\end{tabular}




\begin{tabular}{|c|c|c|c|c|c|c|c|c|c|c|c|c|c|c|c|}
\hline 11. & \multicolumn{3}{|c|}{ TOASO } & \multicolumn{2}{|c|}{2,085} & \multicolumn{3}{|c|}{2,660} & \multicolumn{2}{|l|}{1,761} & \multicolumn{3}{|c|}{1,627} & \multicolumn{2}{|l|}{1,829} \\
\hline 12. & \multicolumn{3}{|c|}{ TRCAS } & \multicolumn{2}{|c|}{2,187} & \multicolumn{3}{|c|}{1,547} & \multicolumn{2}{|l|}{1,783} & \multicolumn{3}{|c|}{1,379} & \multicolumn{2}{|c|}{1,217} \\
\hline 13. & \multicolumn{3}{|c|}{ TUPRS } & \multicolumn{2}{|c|}{3,647} & \multicolumn{3}{|c|}{2,237} & \multicolumn{2}{|l|}{2,173} & \multicolumn{3}{|c|}{2,263} & \multicolumn{2}{|c|}{1,812} \\
\hline 14. & \multicolumn{3}{|c|}{ PRKAB } & \multicolumn{2}{|c|}{2,265} & \multicolumn{3}{|c|}{1,937} & \multicolumn{2}{|l|}{2,029} & \multicolumn{3}{|c|}{2,083} & \multicolumn{2}{|c|}{2,041} \\
\hline 15. & \multicolumn{3}{|c|}{ TTRAK } & \multicolumn{2}{|c|}{3,731} & \multicolumn{3}{|c|}{3,562} & \multicolumn{2}{|l|}{2,643} & \multicolumn{3}{|c|}{2,732} & \multicolumn{2}{|l|}{2,776} \\
\hline 16. & \multicolumn{3}{|c|}{ VESTL } & \multicolumn{2}{|c|}{1,665} & \multicolumn{3}{|c|}{1,231} & \multicolumn{2}{|l|}{1,303} & \multicolumn{3}{|c|}{1,189} & \multicolumn{2}{|c|}{1,270} \\
\hline TOPLAM & Kır & Gri & Yşl & Kir & Gri & Yş1 & Kır & Gri & Yşl & Kir & Gri & Yşl & Kir & Gri & Yşl \\
\hline & 3 & 10 & 3 & 5 & 7 & 4 & 7 & 6 & 3 & 8 & 4 & 4 & 7 & 7 & 2 \\
\hline
\end{tabular}

Altman Z Skor Sonucu yıllar itibari ile değerlendirildiğinde; kırmızı yani yatırım açısından güvensiz, iflas olasılığı yüksek ve finansal başarısı düşük olan işletme sayısının en fazla olduğu yıl sekiz işletme ile 2015 yılındadır. 2015 yılını kırmızı bölgede sıklık göstermesi açısından sırasıyla; 2014 ve 2016 yılları, 2013 yılı ve 2012 yılı izlemektedir. Diğer açıdan ise yeşil bölgede yani yatırım açısından güvenilir, iflas olasılığı düşük ve dolayısıyla finansal başarısı yüksek olan işletme sayısının en fazla olduğu yıllar dört işletme sayısı ile 2013 ve 2015 yıllarıdır. Daha sonra sırası ile; 2012 ve 2014 yılları ile 2016 yılı izlemektedir.

Altman Z Skor Sonucu işletmeler bazında değerlendirildiğinde; 2012 yılı ila 2016 yılı arasındaki 5 yıllık periyotta sürekli olarak yeşil yani güvenilir bölgede yer alan işletme AYGAZ'dır. Finansal başarı açısından AYGAZ'1, 2013 yılı ila 2016 yılı arasında kesintisiz olarak yeşil bölgede yer alarak PNSUT takip etmektedir. PRKAB ise, 2012 yılı ila 2016 yılı arasında sürekli olarak gri bölgede yer alan tek işletmedir. Aynı zamanda; 2012 yılında 3 işletme, 2013 yılında 4 işletme, 2014 yılında 3 işletme, 2015 yılında 4 işletme ve 2016 yılında 2 işletme yeşil bölgede yer almaktadır. Yani söz konusu işletmeler ilgili yıllar itibari ile yatırım açısından güvenilir ve finansal açıdan başarılıdırlar.

\subsection{Springate (1978) S Skor Modeli ile Finansal Başarının İncelenmesi}

1978 yılında Gordon L.V. Springate tarafından geliştirilen Springate S Skor Modeli, Altman Z Skor modelinin geliştirilmiş hali olarak kabul görmektedir. Altman Z Skor modelinde kullanılan dört oran; farklı ağırlıklarla ağırlıklandırılarak, Springate S Modeli oluşturulmuştur. Model uyarınca; S Skor değeri 0,862 değerinin altındaysa işletme iflasa yakın veya finansal açıdan başarısız kabul edilmektedir (Nedzveckas vd., 2003: 58). Model aşağıda yer aldığı gibidir (Springate, 1978: 43).

$$
S=1,03 X 1+3,07 X 2+0,66 \times 3+0,4 X 4
$$

Tablo 7. Kullanılan Değişkenler

\begin{tabular}{|l|l|}
\hline DEĞISSKEN & AÇIKLAMASI \\
\hline X1 & Çalışma Sermayesi / Toplam Varlıklar \\
\hline X2 & Faiz ve Vergi Öncesi Kar / Toplam Varlıklar \\
\hline X3 & Vergi Öncesi Kar / Kısa Vadeli Borçlar \\
\hline X4 & Satışlar / Toplam Varlıklar \\
\hline
\end{tabular}

Kaynak: Springate, 1978: 43. 
Çalışma örneklemimize dahil olan işletmelerin ve 2012 ila 2016 yılları arasında S Skor değerleri hesaplanmış ve sonuçları Tablo 8' de gösterilmiştir.

Tablo 8. Springate S Skor Sonuçları

\begin{tabular}{|l|l|l|l|l|l|l|}
\hline & İŞLTME & $\mathbf{2 0 1 2}$ & $\mathbf{2 0 1 3}$ & $\mathbf{2 0 1 4}$ & $\mathbf{2 0 1 5}$ & $\mathbf{2 0 1 6}$ \\
\hline 1 & AEFES & 0,830 & 1,255 & 0,192 & 0,256 & 0,316 \\
\hline 2 & ARCLK & 0,988 & 1,031 & 1,030 & 0,999 & 0,986 \\
\hline 3 & AYGAZ & 1,308 & 1,279 & 1,258 & 1,276 & 1,352 \\
\hline 4 & CCOLA & 1,404 & 0,902 & 0,829 & 0,591 & 0,483 \\
\hline 5 & HURGZ & 0,822 & 0,045 & $-0,801$ & $-0,071$ & $-0,156$ \\
\hline 6 & IHEVA & 1,015 & $-0,052$ & 1,109 & 1,030 & 0,752 \\
\hline 7 & OTKAR & 0,861 & 0,838 & 0,718 & 3,324 & 0,746 \\
\hline 8 & PETUN & 1,119 & 1,244 & 1,342 & 1,574 & 1,438 \\
\hline 9 & PINSU & 0,340 & $-0,222$ & 0,545 & $-0,425$ & $-0,473$ \\
\hline 10 & PNSUT & 1,466 & 1,115 & 1,193 & 0,492 & 0,897 \\
\hline 11 & TOASO & 1,022 & 0,990 & 0,776 & 0,756 & 0,826 \\
\hline 12 & TRCAS & 1,770 & 0,260 & 0,211 & 0,088 & 0,215 \\
\hline 13 & TUPRS & 1,523 & 0,748 & 0,689 & 0,956 & 0,771 \\
\hline 14 & PRKAB & 0,991 & 0,878 & 0,920 & 0,935 & 0,926 \\
\hline 15 & TTRAK & 2,338 & 2,269 & 1,615 & 1,576 & 1,799 \\
\hline 16 & VESTL & 0,494 & 0,309 & 0,535 & 0,473 & 0,537 \\
\hline $\begin{array}{l}\text { TOPLAM } \\
(>\mathbf{0 , 8 6 2 )}\end{array}$ & & $\mathbf{1 1}$ & $\mathbf{9}$ & $\mathbf{7}$ & $\mathbf{9}$ & $\mathbf{7}$ \\
\hline
\end{tabular}

Tablo 8'de yer alan Springate S Skor sonuçları doğrultusunda; çalışma örneklemine dahil olan 16 işletmeden 11'i, 2012 yılında finansal açıdan başarılıdır. 2013 ve 2015 yıllarında ise, Springate S Skor değerinin 0,862' den büyük olması sebebi ile 9 işletme finansal açıdan başarılı iken 2014 ve 2016 yıllarında 7 işletmenin Springate S Skor değeri 0,862' den büyük ve söz konusu işletmeler finansal açıdan başarılıdırlar.

\subsection{Fulmer (1984) H Modeli ile Finansal Başarının İncelenmesi}

Fulmer vd. H Skor Modeli; 1984 yılında finansal açıdan başarılı 30 işletme ve finansal açıdan başarısız 30 işletme olmak üzere toplamda 60 işletmenin ortalama aktif büyüklüklerine göre seçilerek, Fulmer vd. tarafından ortaya atılmış bir model-dir. Altman Z Skor Modeli ve Springate S Skor Modelinden daha kapsamlı değişkene sahip olan bu model uyarınca $\mathrm{H}$ değerinin sıfırdan büyük olması durumunda işletmeler, iflas olasılığından uzak ve dolayısıyla finansal başarısı yüksek olarak kabul edilmektedir. Model ve değişkenlerin açıklamaları aşağıda yer aldığı gibidir (Fulmer vd., 1984: 26-27).

$$
\begin{gathered}
\mathrm{H}: 5,52 \mathrm{X} 1+0,212 \mathrm{X} 2+0,073 \mathrm{X3}+1,27 \mathrm{X} 4- \\
0,12 \mathrm{X} 5+2,34 \mathrm{X} 6+0,575 \mathrm{X} 7+1,083 \mathrm{X} 8+0,894 \mathrm{X} 9-6,075
\end{gathered}
$$

Tablo 9. Kullanılan Değişkenler

\begin{tabular}{|l|l|}
\hline DEĞIŞKEN & AÇIKLAMASI \\
\hline X1 & Dağıtılmayan Karlar/Toplam Varlıklar \\
\hline X2 & Satışlar/Toplam Varlıklar \\
\hline X3 & Vergi Öncesi Kar/Özkaynak \\
\hline X4 & Nakit/Toplam Borç \\
\hline
\end{tabular}




\begin{tabular}{|l|l|}
\hline X5 & Toplam Borç/Toplam Varlıklar \\
\hline X6 & Kısa Vadeli Borç/Toplam Varlıklar \\
\hline X7 & Log(Maddi Duran Varlıklar) \\
\hline X8 & İşletme Sermayesi/Toplam Borç \\
\hline X9 & Log Faiz ve Vergi Öncesi Kar/Faiz \\
\hline
\end{tabular}

Kaynak: Fulmer vd., 1984: 27.

Çalışma örneklemimize dahil olan işletmelerin ve 2012 ila 2016 yılları arasında Fulmer vd. H değerleri hesaplanmış ve sonuçları Tablo 10' da gösterilmiştir.

Tablo 10. Fulmer vd. H Skor Sonuçları

\begin{tabular}{|l|l|l|l|l|l|l|}
\hline & ISSETME & $\mathbf{2 0 1 2}$ & $\mathbf{2 0 1 3}$ & $\mathbf{2 0 1 4}$ & $\mathbf{2 0 1 5}$ & $\mathbf{2 0 1 6}$ \\
\hline 1 & AEFES & 0,995 & 0,333 & $-0,032$ & $-0,324$ & $-0,294$ \\
\hline 2 & ARCLK & 1,112 & $-0,003$ & 3,223 & 0,154 & 0,273 \\
\hline 3 & AYGAZ & 0,964 & 0,690 & 1,075 & $-0,022$ & 1,417 \\
\hline 4 & CCOLA & 0,842 & 1,034 & $-0,162$ & $-0,233$ & 0,644 \\
\hline 5 & HURGZ & 0,485 & $-0,501$ & $-0,380$ & $-1,545$ & $-0,577$ \\
\hline 6 & IHEVA & $-0,348$ & $-0,292$ & 0,541 & 0,762 & 0,394 \\
\hline 7 & OTKAR & 1,582 & 0,308 & 0,263 & 0,687 & 0,496 \\
\hline 8 & PETUN & 0,060 & 1,150 & 0,888 & 1,093 & 1,030 \\
\hline 9 & PINSU & 0,535 & $-0,356$ & $-0,273$ & 0,333 & $-0,636$ \\
\hline 10 & PNSUT & 2,396 & 0,932 & 1,315 & 1,054 & 1,148 \\
\hline 11 & TOASO & 1,117 & 0,026 & $-0,110$ & $-0,193$ & $-0,129$ \\
\hline 12 & TRCAS & 1,555 & 1,401 & 1,439 & 0,892 & $-0,508$ \\
\hline 13 & TUPRS & 1,494 & 0,155 & 0,115 & 0,212 & 6,073 \\
\hline 14 & PRKAB & 2,163 & 1,021 & 0,989 & 1,147 & 1,735 \\
\hline 15 & TTRAK & 3,497 & 0,995 & 1,863 & 1,223 & 0,877 \\
\hline 16 & VESTL & $-0,965$ & $-1,051$ & $-1,019$ & $-0,094$ & $-0,877$ \\
\hline $\begin{array}{l}\text { TOPLAM } \\
(>\mathbf{0})\end{array}$ & & $\mathbf{1 4}$ & $\mathbf{1 1}$ & $\mathbf{1 0}$ & $\mathbf{1 0}$ & $\mathbf{1 0}$ \\
\hline
\end{tabular}

Tablo 10' da yer alan Fulmer vd. H Skor sonuçları doğrultusunda, 2012 yılında çalışma örneklemine dahil olan 16 işletmeden 14'ü finansal açıdan başarılıdır. 2013 yılında ise H Skor değerinin sıfırdan büyük olması sebebi ile 11 işletme iflas olasılığından uzak ve finansal açıdan başarılıdır. 2014, 2015 ve 2016 yıllarında ise 10'ar işletmenin finansal açıdan başarılı olduğu görülmektedir.

İflas tahmin yöntemleri olarak geliştirilen ve çeşitli rasyoları belirli bilgisayar programları aracılığı ile ağırlıklandırarak birleştiren modellerden Altman Z Skor Modeli; Springate S Skor Modeli ve Fulmer vd. H Skor Modeli kullanılarak çalışma örneklemine dahil olan işletmelerin 2012 yılı ile 2016 yılları arasındaki finansal başarılı ölçülmüştür. Aşağıda yer alan Tablo 11'de yıllar itibari ile kullanılan ve yukarıda söz edilen üç farklı model uyarınca finansal açıdan başarılı olan işletmelere karşılaştırmalı olarak yer verilmiştir.

Kurumsal yönetim derecelendirme notu ve işletmelerin finansal başarıları üç farklı model aracılığı ile ve yıllar itibari ile incelenmiştir. Araştırmanın son kısmında ise, çalışma sorusuna paralel olarak kurumsal yönetim derecelendirme notu ile işletmelerin finansal başarıları arasında ilişkinin incelenmesi amacıyla korelasyon analizi yapılmıştır. 


\subsection{Kurumsal Yönetim Derecelendirme Notu ile Finansal Başarı Arasındaki İlişki}

Kurumsal yönetim derecelendirme notu ile işletmelerin finansal başarıları arasındaki ilişkinin incelenmesi amacıyla, SPSS 22.0 programı kullanılarak korelasyon analizi yapılmıştır. Bunun için öncelikle verilerin normal dağılıma uygun olup olmadığı incelenmiş ve verilen normal dağılıma uygun olmadığı tespit edilmiştir. Bu sebeple, Spearman's Testi kullanılarak korelasyon analizi gerçekleştirilmiştir. Korelasyon analizi sonucuna Tablo 11' de yer verilmiştir.

Tablo 11. Korelasyon Analizi Sonucu

\begin{tabular}{|c|c|c|c|c|c|c|}
\hline & & & ALTMANZ & SPRINGATE & FULMER & KYDN \\
\hline \multirow{12}{*}{ Spearman's rho } & \multirow{3}{*}{ ALTMANZ } & Correlation Coefficient & 1,000 &, $731^{* *}$ &, $587^{* *}$ &,$- 231^{*}$ \\
\hline & & Sig. (2-tailed) & & , 000 & ,000 & ,040 \\
\hline & & $\mathrm{N}$ & 80 & 80 & 80 & 80 \\
\hline & \multirow{3}{*}{ SPRINGATE } & Correlation Coefficient &, $731^{* *}$ & 1,000 & ,621 &,$- 300^{* *}$ \\
\hline & & Sig. (2-tailed) & , 000 & & ,000 & ,007 \\
\hline & & $\mathrm{N}$ & 80 & 80 & 80 & 80 \\
\hline & \multirow{3}{*}{ FULMER } & Correlation Coefficient &, $587^{* *}$ & $621^{* *}$ & 1,000 &,$- 356^{* *}$ \\
\hline & & Sig. (2-tailed) & , 000 & ,000 & & ,001 \\
\hline & & $\mathrm{N}$ & 80 & 80 & 80 & 80 \\
\hline & \multirow{3}{*}{ KYDN } & Correlation Coefficient &,$- 231^{*}$ &,$- 300^{* *}$ &,$- 356^{* *}$ & 1,000 \\
\hline & & Sig. (2-tailed) & , 040 & ,007 & ,001 & \\
\hline & & $\mathrm{N}$ & 80 & 80 & 80 & 80 \\
\hline
\end{tabular}

**. Correlation is significant at the 0.01 level (2-tailed).

*. Correlation is significant at the 0.05 level (2-tailed).

Tablo 11' de görüldügü üzere kurumsal yönetim derecelendirme notu ile (KYDN) sirası ile Altman Z Skor Modeli (ALTMAN Z), Springate S Modeli (SPRINGATE) ve Fulmer H Modeli (FULMER) arasındaki ilişki negatif yönlü ve anlamlıdır. Anlamlılık katsayıları ise, sırasıyla 0,040, 0,007 ve 0,001'dir. Daha geniş bir açıdan işletmelerin kurumsal yönetim derecelendirme notu arttıkça veya kurumsal yönetim ilkelerine uyum düzeyleri arttıkça iflas olasılıkları her üç modelde de azalmakta ve dolayısıyla finansal başarıları artmaktadır.

\section{SONUÇ}

$\mathrm{Bu}$ çalışma kapsamında; kurumsal yönetim endeksinde yer alan imalat işletmelerinin kurumsal yönetim derecelendirme notu ile finansal başarıları arasındaki ilişki incelenmiştir. Ayrıca bu çalışma sonucunda, hem finansal hem de finansal olmayan veriler değerlendirme kapsamına alınarak, birbirleri ile ilişkileri ortaya konmuştur. Bu kapsamda; işletmelerin kurumsal yönetim derecelendirme notu ile finansal başarıları arasında anlamlı ve negatif yönlü bir ilişki tespit edilmiştir. Daha geniş bir anlatımla, işletmelerin kurumsal yönetim derecelendirme notu arttıkça, finansal başarıları artmakta ve dolayısıyla finansal performansları artmaktadır. $\mathrm{Bu}$ noktada, kurumsal yönetim derecelendirme notu ile işletmelerin finansal başarıları arasında negatif yönlü bir ilişki olduğunu öne süren $\mathrm{H} 1$ hipotezimiz kabul edilerek, H2 hipotezimiz reddedilmiştir. Çalışma sonuçlarımıza paralel 
olarak, Ege vd. (2013) tarafından Topsis Yöntemi kullanılarak yapılan çalışmada, işletme performansları ile kurumsal yönetim derecelendirme notu arasında negatif yönlü bir ilişki tespit edilmiştir. Benzer doğrultuda, Acaravcı vd. (2015) çalışmalarında, işletme performansları ile kurumsal yönetim uygulamaları arasında ilişki olduğunu ifade etmişlerdir. Ancak Okan vd. (2014) tarafından yapılan çalışmada, yönetim kurulu büyüklüğünün, finansal performans üzerinde anlamlı ve pozitif yönlü bir etkisinin olduğu ifade edilmiştir. Aynı zamanda, Yıldız (2014) çalışmasında, kurumsal yönetim endeksi ile işletme derecelendirmesi arasında pozitif yönlü bir ilişki tespit etmemiştir.

Çalışma kapsamına sadece imalat sektörünün dahil edilmesi sebebi ile çalışma sonuçlarının tüm sektörler için genellenmesi hatalı sonuçlara ulaşılmasına sebep olabilecektir. $\mathrm{Bu}$ durum çalışmanın kısıtını oluşturmakla birlikte, çalışma sonuçlarımız sadece imalat sektörü açısından değerlendirilmelidir.

Sonraki çalışmalarda BİST endeksinde yer alan farklı bir sektör çalışma kapsamına dahil edilebilir veya farklı sektörler aracılığı ile karşılaştırma yapılarak, sektörler arası farklılıklar ortaya konabilir. Ayrıca işletmelerin finansal başarılarını değerlendirmek amacıyla kullanılan modellerden farklı bir model veya modeller kullanılarak karşılaştırılabilir.

\section{KAYNAKLAR}

Acaravc1, Songül K.- Kandir, Serkan Y. - Zelka, Ahmet (2015), "Kurumsal Yönetimin BIST Şirketlerinin Performanslarına Etkisinin Araştırılması”, Niğde Üniversitesi İktisadi ve İdari Bilimler Fakültesi Dergisi, 8(1), ss. 171-183.

Akdoğan, Nalan- Gülhan, Ozan - Aktaş, Melike (2016), “Borsa İstanbul 'da Kurumsal Yönetim İlkelerine Uyum Düzeyinin Bağımsız Denetçi Görüşlerine Etkisi ve Bağımsız Denetim Piyasa Yapısı Ulusal Pazar-Gözaltı Pazarı Kurumsal Yönetim Endeksi Karşılaştırması”, Muhasebe Bilim Dünyası Dergisi, 18(Özel Sayı-1), ss. 1-22.

Altman, Edward (1968), "Financial Ratios, Discriminant Analysis and the Prediction of Corporate Bankruptcy”, The Journal of Finance, 23(4), ss. 589-609.

Bozkurt, İbrahim (2014), “ İflas Olasılı̆̆ı ile Sistematik Risk İlişkisinin İncelenmesi ve Etkin İflas Göstergesi Modellerinin Tespiti: BİST’ de Ampirik Bir Uygulama”, Süleyman Demirel Üniversitesi İktisadi ve İdari Bilimler Fakültesi Dergisi, 19(4), ss. 127- 142.

Ege, İlhan- Topaloğlu, Emre E. - Özyamanoğlu, Murat (2013), "Finansal Performans ile Kurumsal Yönetim Notları Arasındaki İlişki: BİST Üzerine Bir Uygulama”, Akademik Araştırmalar ve Çalışmalar Dergisi / Journal of AcademicResearches and Studies, 5(9), ss. 100-117.

Fulmer, JG.- Moon, JE. -Gavin, TA.- Erwin, MJ.,(1984), “A Bankruptcy Classification Model For Small Firms”, Journal of Commercial Bank Lending, 66(11), pp. 25-37.

İskenderoğlu, Ömer - Karakozak, Özlem (2013), “2008 Küresel Finansal Krizinin Finansal Oranlar Üzerine Etkisi: BIST’ de İşlem Gören İmalat Sanayi İşletmeleri Üzerine Bir 
Uygulama”, Dokuz Eylül Üniversitesi İktisadi ve İdari Bilimler Fakültesi Dergisi, 28(2), ss. 99-129.

Kulalı, İhsan (2016), “Altman Z Skor Modelinin BİST Şirketlerinin Finansal Başarısızlık Riskinin Tahmin Edilmesinde Uygulanması”, Uluslararası Yönetim İktisat ve İşletme Dergisi, 22(27), ss. 283-291.

KYD ve OECD. 2005. OECD Kurumsal Yönetim İlkeleri 2004. İstanbul: KYD Yayınları.

Miller, Warren (2009), Comparing models of corporate bankruptcy prediction: Distance to default vs. Z-score. Morningstar, Inc.

Muigai, Robert Gitau (2016), Effect of capital structure on financial distress of non-financial companies listed in Nairobi securities exchange. Dissertation of Doctor of Philosophy in Finance in the Jomo Kenyatta University of Agriculture and Technology.

Nedzveckas, J., Jurkevičius, E. - Rasimavičius, G. (2003), “Testing of Bankruptcy Prediction Met-hodologies for Lithuanian Market”, Mokslo Taikomieji Tyrimai Lietuvos Kolegijose, 3(1), pp. 54-64.

Okan, Tarhan- Sarı, Selcen ve Nas, Tülay İ. (2014), "Yönetim Kurulu Yapısı ile Finansal Performans Arasındaki İlişkide Uluslararası Çeşitlenmenin Aracılık Etkisi”, İstanbul Üniversitesi İşletme Fakültesi İşletme İktisadı Enstitüsü Yönetim Dergisi, 25(77), ss. 39-78.

Ross, Stephen A- Westerfield, Randolph W.- Jaffe, Jeffrey, (2005), Corporate Finance, 3. Bask1, Irwin, McGraw-Hill.

Sermaye Piyasası Kurulu. (2005, Şubat). Kurumsal Yönetim İlkeleri. Ankara, Türkiye.

Shleifer, Andrei- Vishny, Robert W. (1996). A Survey Of Corporate Governance. National Breau of Economic Research. NBER Working Paper 5554.

SPK, (2). (2005), Sermaye Piyasasında Derecelendirme Faaliyeti ve Derecelendirme Kuruluşlarına İlişkin Esaslar Tebliği.

Springate Gordon LV. (1978), "Predicting the possibility of failure in a Canadian firm. Unpublished MBA Res. project, Simon Fraser Univ”, January, pp. 42-47.

Yıldız, Ayşe (2014), "Kurumsal Yönetim Endeksi ve Altman Z Skoruna Dayalı Lojistik Regresyon Yöntemleriyle Şirketlerin Kredi Derecelendirmesi”, Süleyman Demirel Üniversitesi İktisadi ve İdari Bilimler Fakültesi Dergisi, 19(3), ss. 71-89. 
